\title{
Revisiting the five-facet structure of mindfulness
}

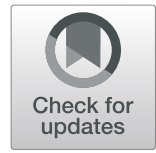

\author{
Johannes Alfons Karl ${ }^{1 *}$ and Ronald Fischer ${ }^{1,2}$
}

\begin{abstract}
The current study aimed to replicate the development of the Five-Facet Mindfulness Questionnaire (FFMQ) in a sample of 399 undergraduate students. We factor analyzed the Mindful Attention and Awareness Questionnaire (MAAS), the Freiburg Mindfulness Scale, the Southampton Mindfulness Questionnaire (SMQ), the Cognitive Affective Mindfulness Scale Revised (CAMS-R), and the Kentucky Inventory of Mindfulness Skills (KIMS), but also extended the analysis by including a conceptually related measure, the Philadelphia Mindfulness Scale (PHLMS), and a conceptually unrelated measure, the Langer Mindfulness Scale (LMS). Overall, we found a partial replication of the five-factor structure, with the exception of non-reacting and non-judging which formed a single factor. The PHLMS items loaded as expected with theoretically related factors, whereas the LMS items emerged as separate factor. Finally, we found a new factor that was mostly defined by negatively worded items indicating possible item wording artifacts within the FFMQ. Our conceptual validation study indicates that some facets of the FFMQ can be recovered, but item wording factors may threaten the stability of these facets. Additionally, measures such as the LMS appear to measure not only theoretically, but also empirically different constructs.
\end{abstract}

\section{Introduction}

How robust are our current conceptualizations of mindfulness? Should dispositional mindfulness be thought of as a one-dimensional construct or are there multiple facets and, if yes, how many? This question is important because different traditions of Eastern and Western mindfulness exist. Yet, it is unclear how sensitive current measures are to those distinctions or whether those approaches can be integrated. Dispositional mindfulness is defined as "paying attention in a particular way: on purpose, in the present moment, non-judgmentally" (KabatZinn, 1994, p.4) and it has been measured with a number of instruments (Bergomi, Tschacher, \& Kupper, 2013b, 2013a; Sauer et al., 2013). Trying to find a common structure, Baer, Smith, Hopkins, Krietemeyer, and Toney (2006) factor analyzed 112 items from the Mindful Attention and Awareness Scale(MAAS), the Kentucky Inventory of Mindfulness Skills (KIMS), the Freiburg Mindfulness Inventory (FMI), the Cognitive Affective

\footnotetext{
*Correspondence: johannes.karl@vuw.ac.nz

${ }^{1}$ Victoria University of Wellington, Wellington, New Zealand

Full list of author information is available at the end of the article
}

Mindfulness Scale (CAMS), and the Southampton Mindfulness Questionnaire (SMQ) (Baer et al., 2006) and reported a five-factor solution of mindfulness when using principal axis factoring with an oblique rotation. Based on this emergent empirical structure, they developed the Five Facet Mindfulness Questionnaire (FFMQ) using the 39 highest loading items from the original pool of items. The identification of these five common dimensions across a number of widely used instruments has led to the implicit recognition and acceptance of a multidimensional model of mindfulness (i.e., the Five-Facet Model of Mindfulness, FFMM), with the FFMQ considered to be the prime measure of an underlying multidimensional model of mindfulness (which we call FFMM). Given the widespread use of the instrument and the theoretical implications of the conceptualization of mindfulness, it is important to verify and replicate the emergence of the FFMM even when using different mindfulness measures and with different samples to assess the appropriateness of the FFMQ to measure mindfulness and the validity of the FFMM as a conceptual model of mindfulness.

(c) The Author(s). 2020 Open Access This article is licensed under a Creative Commons Attribution 4.0 International License, which permits use, sharing, adaptation, distribution and reproduction in any medium or format, as long as you give appropriate credit to the original author(s) and the source, provide a link to the Creative Commons licence, and indicate if changes were made. The images or other third party material in this article are included in the article's Creative Commons licence, unless indicated otherwise in a credit line to the material. If material is not included in the article's Creative Commons licence and your intended use is not permitted by statutory regulation or exceeds the permitted use, you will need to obtain permission directly from the copyright holder. To view a copy of this licence, visit http://creativecommons.org/licenses/by/4.0/. 
Since this seminal analysis by Baer et al. (2006), other scales measuring dispositional mindfulness, such as the Philadelphia Mindfulness Scale (Cardaciotto, Herbert, Forman, Moitra, \& Farrow, 2008) and the Langer Mindfulness Scale (Pirson, Langer, Zilcha, \& Zilcha, 2018), have been developed. These scales were not included in the original analysis conducted by Baer et al. (2006), but a rigorous replication of the steps taken by Baer et al. (2006) including these scales may indicate the robustness of both the theoretical model of the FFMM and the empirical validity of the FFMQ. The aim of the current study is to examine the comprehensiveness and robustness of the five-factor structure by examining whether the similar five facets emerge if the factor analysis is extended to those new measures.

\section{History of mindfulness assessment}

To provide some historical context, the source scales of the FFMQ were supposed to capture a number of related but distinct dimensions, initially derived from an adaptation of Eastern philosophical thinking to Western audiences (Baer et al., 2006; Kucinskas, 2018). The MAAS (Brown \& Ryan, 2003) assesses the lack of attention to one's emotions, thoughts, sensations, and behaviors in general and is proposed to measure present-awareness (Brown \& Ryan, 2003; Carlson \& Brown, 2005). The KIMS (Baer, Smith, \& Allen, 2004) conceptualizes mindfulness as a four-dimensional construct with acting with awareness, accept without judgment, describing, and observing facets. The revised FMI (Walach, Buchheld, Buttenmüller, Kleinknecht, \& Schmidt, 2006) assesses a general factor of nonjudgmental present-moment awareness, therefore adding the lack of self-evaluation as an important component of the construct. The CAMS-R (Feldman, Hayes, Kumar, Greeson, \& Laurenceau, 2007) assesses four facets of mindfulness: self-regulation of attention, orientation to present-moment experience, awareness of experience, and accepting or non-judging attitude toward experience. The SMQ (Chadwick et al., 2008) assesses mindfulness in response to distressing images, focusing on decentered awareness, staying open to difficult experience, non-judgmental acceptance, and seeing difficult cognitions as transient mental events without reacting to them to measure a single score of mindfulness.

Despite their differences, a factor analysis of these instruments using principal axis factoring with an oblique rotation based on all 112 items suggested that five main facets were sufficient to represent the data (Baer et al., 2006). Of the original set of 112 items, 64 items loaded substantially on one of the five facets. The observing facet measures the awareness of internal experiences (emotions, cognitions) and external experiences (sounds, sights, and smells). The describing facet measures the tendency and ability to describe these internal and external experiences with words. The acting with awareness facet measures the tendency to bring full awareness and undivided focus to actions and experiences. The nonjudging facet measures the tendency to refrain from evaluating inner experiences. The non-reactivity facet measures the tendency to accept emotions and states as transient and refrain from reacting to them. All these facets seem to capture elements that were central to the Eastern philosophical foundations of mindfulness, except that the spiritual and religious components have been excluded (Kabat-Zinn, 1994; Kucinskas, 2014).

\section{Mindfulness assessment since the development of the FFMQ}

Since the development of the FFMQ, a number of additional measures have been proposed. One such novel measure is the Philadelphia Mindfulness Scale (PHLMS, Cardaciotto et al., 2008) which measures presentmoment awareness and acceptance as two related but empirically distinct concepts. These two dimensions maintain a Buddhist philosophical approach to mindfulness, and previous research has shown this measure to be conceptually related to the FFMQ (Siegling \& Petrides, 2016).Therefore, we expect that the Philadelphia Mindfulness Scale (PHLMS) items will emerge jointly with other related items and can be integrated in the five-facet theoretical model .

However, non-Buddhist measures of mindfulness have also been proposed more recently, most notably the Langer Mindfulness Scale (LMS, Pirson et al., 2018). Pirson et al. (2012) defined mindfulness as "a mindset of openness to novelty in which the individual actively constructs novel categories and distinctions" (Pirson et al., 2012, p.3). This Western approach to mindfulness is more focused on the socio-cognitive elements of mindfulness, highlighting that mindfulness is typically goaloriented and involves problem-solving and other cognitive exercises. Instead of the more meditativecontemplative aspect of Eastern mindfulness conceptualizations, it explicitly draws on the external, material, and social context of the individual. Their new measure is supposed to capture three-facets: novelty-production, novelty-seeking, and engagement. From our perspective, it is interesting to note that the philosophical orientation and the relevant motivational core of mindfulness are different, but the constituent cognitive and attentional elements might be similar. Not surprisingly, while theoretically and philosophically distinct, the LMS and the overall score of the FFMQ have been found to correlate moderately at $r=.33$ to .37 (Pirson et al., 2018; Siegling \& Petrides, 2014). This raises the question whether these Western-based mindfulness components can be integrated in the existing structure of the FFMQ. Given the 
theoretical philosophical background of this Western mindfulness tradition, we expect the items of LMS would emerge on distinct factor(s) in a joint factor analysis of mindfulness constructs. One of the interesting questions is how distinct these Western-derived mindfulness dimensions are when analyzed together with instruments that have been inspired by Eastern philosophy.

\section{Current research}

In summary, the FFMQ has emerged as the prime measure to capture the FFMM (Baer et al., 2006). The FFMQ has been derived in a bottom-up approach by factor analyzing pre-existing measures (Baer et al., 2006). This empirically driven approach requires confirmation and replication to assess the theoretical appropriateness of the FFMQ as the principal measure of a multidimensional mindfulness construct (Magnusson, 1992; Tellis, 2017). While previous studies have employed a confirmatory strategy using only the final FFMQ (Gu et al., 2016; Williams, Dalgleish, Karl, \& Kuyken, 2014), no study to date has undertaken a conceptual replication of the generation of the underlying FFMM. One reason this is important is to examine the potential presence of item wording effects in the current measurement of mindfulness (for studies reporting such method factors in the FFMQ see: Aguado et al., 2015; Van Dam, Hobkirk, Danoff-Burg, \& Earleywine, 2012). Further, these studies have shown that a bi-factor model of the FFMQ, in which all items load onto a general factor of mindfulness and their individual facets while including wording factors, substantially improved the structure. This indicates that beyond their assignment to individual facets mindfulness items might share some common variance that could be explained by a general factor (for a discussion of this interpretation of a bi-factor model see: Bonifay, Lane, \& Reise, 2017). In the FFMQ, this factor could represent Buddhist-inspired mindfulness raising the question if a similar bi-factor model emerges when Western-oriented measures of mindfulness are included. Investigating the emergent structure of the mindfulness measures is also of interest because both novel Buddhist inspired as well as Western-oriented measures of mindfulness have been developed since the publication of the FFMQ, raising important questions both about the comprehensiveness of the FFMM and the appropriateness of the FFMQ to measure such a multidimensional model of mindfulness. The current study aims to extend the current research on the dimensionality of mindfulness by re-examining the emergence of multi-dimensional mindfulness structures including recent measures of mindfulness.

\section{Methods \\ Participants}

We sampled 404 undergraduate students at Victoria University of Wellington. Five participants $(1.24 \%$ of the total) started the questionnaire but did not finish it. Due to the low number of participants that did not answer the survey completely, we removed those five individuals from the dataset, leaving an effective sample size of 399. The average age of the participants was $19.21(S D=3.93)$, and $68.92 \%$ of the total sample were female.

Previous mindfulness practice of the total sample, 8.77\% reported previous mindfulness experience, $9.52 \%$ reported yoga experience, and $10.03 \%$ reported meditation experience. This sample composition in terms of age and mindfulness experience is comparable to the original FFMQ study (Baer et al., 2006). Due to the low number of participants with previous meditation experience, we did not perform separate analysis comparing meditation practitioners and participants with no meditation experience.

Procedure Participants filled out an online survey on Qualtrics (the Qualtrics survey file and a word version of the survey are available on the OSF: https:// osf.io/k2m35/). The mindfulness scales were presented as part of a larger survey pack. The survey pack also contained measures of personality (Soto \& John, 2017), reinforcement sensitivity (Corr \& Cooper, 2016), values (Schwartz et al., 2012), impression management (Blasberg, Rogers, \& Paulhus, 2014), selfdeception (Paulhus \& Reid, 1991), satisfaction with life (Diener, Emmons, Larsen, \& Griffin, 1985), flourishing (Diener et al., 2010), and a number of behavioral tasks (pen choices) to assess group conformity. The complete data are available on the OSF. Individuals participated as part of an Introduction to Psychology course and received course credit.

\section{Open science statement}

The current study reports an exploratory analysis into the structure of mindfulness. Recent studies (e.g., Silberzahn et al., 2018) demonstrate the impact of analytic freedom on reported outcomes. We aim to provide maximum transparency of the analysis by providing the full raw data set, the analytic code, and all materials associated with the study on the Open Science Framework (https://osf.io/k2m35/). The current study was part of a larger pack of surveys administered to the participants. 


\section{Instruments}

The Mindful Attention and Awareness Scale The MAAS (Brown \& Ryan, 2003) uses 15 items that a participant rates on a scale from 1 (almost always) to 6 (almost never). Example items are "I do jobs or tasks automatically, without being aware of what I'm doing." and "I find myself listening to someone with one ear, doing something else at the same time." Lower scores on these items indicate greater mindfulness.

The Southampton Mindfulness Questionnaire We used the 16-item SMQ (Chadwick et al., 2008), with a 7point Likert scale ranging from 1 (strongly disagree) to 7 (strongly agree). The questionnaire was preceded by the statement: "Usually when I experience distressing thoughts and images..." Example items are "I am able just to notice them without reacting." and "They take over my mind for quite a while afterwards."

The Cognitive and Affective Mindfulness ScaleRevised The Cognitive and Affective Mindfulness ScaleRevised (CAMS-R) is a 12-item measure with four subcomponents (Feldman et al., 2007). Participants answered the items on a 4-point Likert scale ranging from 1 (rarely/not at all) to 4 (almost always). Example items for the individual subcomponents are "It is easy for me to concentrate on what I am doing." (attention), "I am able to focus on the present moment." (present focus), "It's easy for me to keep track of my thoughts and feelings." (awareness), "I can tolerate emotional pain." (acceptance).

The Freiburg Mindfulness Inventory We used the 14item FMI (Walach et al., 2006) with the original 4-point Likert scale ranging from 1 (rarely) to 4 (almost always). Example items are "I am open to the experience of the present moment." and "I sense my body, whether eating, cooking, cleaning or talking." In their original study Baer et al. (2006) used an earlier developmental version of the FMI which had 30 items.

Kentucky Inventory of Mindfulness Skills We used the 39-item KMI to assess a multi-dimensional conceptualization of mindfulness (Baer et al., 2004). The items are rated on a 5-point Likert scale ranging from 1 (never or very rarely true) to 5 (very often or always true). Example items are "I'm good at finding the words to describe my feelings." (describing); "I notice changes in my body, such as whether my breathing slows down or speeds up." (observing); "When I do things, my mind wanders off and I'm easily distracted." (acting with awareness); "I criticize myself for having irrational or inappropriate emotions." (non-judging).
The Langer Mindfulness Scale We used the 14-item LMS (Pirson et al., 2018) to assess a multi-dimensional conceptualization of socio-cognitive mindfulness. The items are rated on a 7-point Likert scale ranging from 1 (strongly disagree) to 7 (strongly agree). Example items are "I am rarely alert to new developments." (engagement); "I make many novel contributions." (novelty producing); "I like to investigate things." (novelty seeking).

We report the reliabilities and scale descriptives of all measures in Table 1 . We decided to evaluate reliability using $\omega$, the greatest lower bound (GLB), and coefficient $\mathrm{H}(\mathrm{H})$. These indicators have been shown in previous research to provide better estimations of reliability compared to $\alpha$ (McNeish, 2018; Trizano-Hermosilla \& Alvarado, 2016). We nevertheless report $\alpha$ for comparison purposes. Both $\alpha$ and $\omega$ are reported with bootstrapped $95 \%$ confidence intervals. All reliability coefficients were obtained using the userfriendlyscience package (version 0.7.2) in R (Peters, 2018). The reliabilities were acceptable (values above .7), except for LMS engagement, CAMS awareness, CAMS acceptance, and CAMS present focus.

\section{Analytical approach}

We first examined the theoretically proposed fit for each mindfulness scale using separate CFAs. This analysis provides important information on the internal validity of each of these measures and therefore, offers important background information for understanding the replication study. For each scale, we fitted the structures which were proposed by the original authors of the measures. Specifically, we fitted a uni-dimensional model for the FMI, the SMQ, and the MAAS, respectively. For the PHLMS, we fitted a model with two correlated firstorder factors (acceptance, awareness). For the LMS, we fitted a model with three correlated first-order factors (novelty producing, novelty seeking, engagement). For the $K I M S$, we fitted a model with four first-order factors (observing, describing, non-judging, and acting with awareness) and a second-order factor representing mindfulness. For the $C A M S-R$, we fitted a model with four first-order factors (attention, present focus, awareness, and acceptance) and a second-order factor representing overall mindfulness. Therefore, we have a number of single factor models (FMI, SMQ, MAAS); a two-factor model (PHLMS); a three-factor model (LMS); and two four-factor models with a second-order mindfulness factor (CAMS-R, KIMS).

Due to multivariate non-normality of our data, all models were fitted using an WLSMV estimator rather than parceling items (Li, 2016; Maydeu-Olivares, 2017). We use the following fit indices: $\mathrm{A} \chi^{2} /$ degrees of freedom ratio of $<5$ is considered acceptable (Wheaton, Muthen, Alwin, \& Summers, 1977), CFI and $\gamma$ (with .90 
Table 1 Reliability and scale descriptives of the mindfulness measures

\begin{tabular}{|c|c|c|c|c|c|c|c|c|c|c|}
\hline & M & SD & $a$ & a low & a high & $\omega$ & $\omega$ low & $\omega$ high & GLB & $\mathrm{H}$ \\
\hline CAMS-R attention & 2.20 & 0.62 & .731 & .679 & .775 & .731 & .671 & .772 & .726 & .735 \\
\hline CAMS-R present focus & 2.48 & 0.57 & .491 & .396 & .573 & .509 & .385 & .595 & .518 & .528 \\
\hline CAMS-R awareness & 2.39 & 0.62 & .581 & .504 & .656 & .590 & .506 & .655 & .595 & .611 \\
\hline CAMS-R acceptance & 2.65 & 0.67 & .605 & .517 & .666 & .606 & .529 & .664 & .603 & .614 \\
\hline Freiburg Mindfulness Inventory & 2.55 & 0.47 & .823 & .796 & .848 & .826 & .794 & .849 & .856 & .853 \\
\hline Langer Mindfulness Scale engagement & 4.97 & 0.97 & .598 & .514 & .672 & .605 & .518 & .668 & .616 & .626 \\
\hline Langer Mindfulness Scale novelty producing & 4.30 & 0.93 & .653 & .591 & .709 & .689 & .637 & .736 & .742 & .790 \\
\hline Langer Mindfulness Scale novelty seeking & 5.33 & 0.92 & .761 & .713 & .801 & .761 & .715 & .799 & .786 & .781 \\
\hline MAAS & 3.46 & 0.73 & .837 & .810 & .862 & .839 & .811 & .863 & .839 & .865 \\
\hline Philadelphia Mindfulness Scale awareness & 3.52 & 0.62 & .811 & .779 & .839 & .812 & .777 & .839 & .865 & .830 \\
\hline Philadelphia Mindfulness Scale acceptance & 3.47 & 0.78 & .876 & .855 & .895 & .876 & .852 & .894 & .891 & .886 \\
\hline Southampton Mindfulness Questionnaire & 3.79 & 0.84 & .865 & .844 & .885 & .867 & .843 & .886 & .902 & .878 \\
\hline Kentucky Mindfulness Inventory observing & 3.24 & 0.62 & .810 & .779 & .838 & .810 & .777 & .839 & .832 & .814 \\
\hline Kentucky Mindfulness Inventory describing & 3.05 & 0.77 & .870 & .847 & .888 & .875 & .854 & .894 & .882 & .895 \\
\hline Kentucky Mindfulness Inventory acting with awareness & 2.71 & 0.49 & .657 & .600 & .710 & .645 & .572 & .705 & .758 & .787 \\
\hline Kentucky Mindfulness Inventory non-judging & 2.86 & 0.77 & .863 & .840 & .884 & .869 & .843 & .887 & .908 & .892 \\
\hline
\end{tabular}

Notes: $\alpha$ and $\omega$ are reported with $95 \%$ bias corrected confidence intervals GLB greatest lower bound, $H$ coefficient $H$

defined as threshold for acceptable fit and .95 defined as threshold for good fit, Marsh, Hau, \& Wen, 2004), RMSEA (with less than $0.01,0.05$, and 0.08 to indicate excellent, good, and mediocre fit respectively, MacCallum, Browne, \& Sugawara, 1996), and SRMR (acceptable fit is indicated by values less than $.08, \mathrm{Hu} \&$ Bentler, 1999). We further report $X^{2}$ and degrees of freedom for each model, but do not focus on these indicators due to the known dependency on sample size.

Second, we ran an exploratory factor analysis using all mindfulness items to investigate the structure across all items and all instruments. We started off with a parallel analysis using the complete pool of items from the all mindfulness scales to determine the optimal number of components while accounting for components occurring due to random chance. We used Glorfeld's (1995) conservative approach instead of Horn's (1965) parallel analysis. We retained components which had eigenvalues greater than one after adjusting the initial eigenvalues for the eigenvalues observed in a random data set.

To examine the unfolding of the factor structure (see Goldberg, 2006), we implemented an iterative process in which we ran a PCA with 1 up to the number of factors proposed by the parallel analysis. After extracting each set of components using a principal component analysis with a varimax rotation using the psych package (version 1.8.12) in R (Revelle, 2018), we correlated participants' scores on these components with the previously extracted component (Goldberg, 2006). This approach provides insight into the pattern of emergence of components (for examples see: De Raad et al., 2014; De Raad \& Van Oudenhoven, 2008, 2011) .

\section{Results}

\section{Confirmatory factor analysis}

The CFA of the individual scales showed acceptable fit for the FMI, the MAAS, and the CAMS-R. Interestingly, the CAMS- $\mathrm{R}$ showed good fit while its individual scales had poor reliability. The other measures showed less than acceptable overall fit (see Table 2). Compared to previous studies using these measures, we found that in our sample the FMI and CAMS-R showed better fit, whereas the PHLMS, KIMS, SMQ, and LMS showed worse fit compared to other studies (we include a table reporting fit statistics from previous studies which we used to compare our results against on the OSF).

\section{Factorial structure}

The parallel analysis suggested 6 components (adjusted eigenvalues $15.61,8.27,2.39,1.55,1.37,1.27)$. We therefore extracted 1 to 6 components based on the parallel analysis explaining $34 \%$ of the total variance. For the 6component structure, we report the highest negative and positive loading items for each component in Table 3 to allow for easier interpretation. Additionally, the full loading matrix for the 6-component solution can be found in Table 4. We only interpreted loadings $>.40$ when examining the loading matrices of the items. No items were deleted. Due to space constraints, we made the full rotated component matrices for all solutions 
Table 2 CFA fit of the individual mindfulness measures

\begin{tabular}{llllllll}
\hline Measure & $X^{2}$ & $\mathrm{df}$ & $X^{2} / \mathrm{df}$ & CFI & RMSEA & Gamma & Overall fit \\
\hline Freiburg Mindfulness Inventory & 168.288 & 77 & 2.186 & .922 & .055 & .968 & Good \\
Langer Mindfulness Scale & 190.636 & 74 & 2.576 & .881 & .063 & .96 & Poor \\
MAAS & 156.588 & 90 & 1.74 & .944 & .043 & .978 & Good \\
Philadel phia Mindfulness Scale & 379.246 & 169 & 2.244 & .884 & .056 & .95 & Poor \\
Southampton Mindfulness Questionnaire & 435.428 & 104 & 4.187 & .765 & .089 & .906 & Poor \\
Kentucky Mindfulness Inventory & 1407.766 & 696 & 2.023 & .766 & .051 & .916 & Poor \\
CAMS-R & 129.752 & 50 & 2.595 & .909 & .063 & .968 & Good
\end{tabular}

Notes: all models were fitted with a WLSMV estimator. Overall fit is assessed as good if CFI $>.90$, RMSEA $<.80$, and SRMR $<.08$

Table 3 Components extracted with their highest positive and negative loading items

\begin{tabular}{|c|c|c|c|}
\hline Component & Name & Positive & Negative \\
\hline$\overline{1 \_1}$ & $\begin{array}{l}\text { Non-judgmental } \\
\text { awareness }\end{array}$ & I am able to accept the thoughts and feelings I have. & $\begin{array}{l}\text { I think some of my emotions are bad or inappropriate and I } \\
\text { shouldn't feel them. }\end{array}$ \\
\hline $2 \_1$ & $\begin{array}{l}\text { Judgmental non- } \\
\text { awareness }\end{array}$ & I tell myself that I shouldn't be feeling the way I'm feeling. & I am able to accept the thoughts and feelings I have. \\
\hline $2 \_2$ & Observing & I intentionally stay aware of my feelings. & I am not an original thinker. \\
\hline $3 \_1$ & Non-judgment & I am friendly to myself when things go wrong. & $\begin{array}{l}\text { I think some of my emotions are bad or inappropriate and I } \\
\text { shouldn't feel them. }\end{array}$ \\
\hline $3 \_2$ & Observing & $\begin{array}{l}\text { When talking with other people, I am aware of the emotions I } \\
\text { am experiencing. }\end{array}$ & I am not an original thinker. \\
\hline $3 \_3$ & Describing/focus & $\begin{array}{l}\text { When someone asks how I am feeling, I can identify my } \\
\text { emotions easily. }\end{array}$ & It's hard for me to find the words to describe what I'm thinking. \\
\hline $4 \_1$ & Non-judgment & I am friendly to myself when things go wrong. & $\begin{array}{l}\text { Usually when I experience distressing thoughts and images... I get } \\
\text { angry that this happens to me. }\end{array}$ \\
\hline $4 \_2$ & Observing & $\begin{array}{l}\text { When I walk outside, I am aware of smells or how the air feels } \\
\text { against my face. }\end{array}$ & I am rarely aware of changes. \\
\hline $4 \_3$ & Self-criticism & I tell myself that I shouldn't be feeling the way I'm feeling. & $\begin{array}{l}\text { It seems I am "running on automatic" without much awareness of } \\
\text { what I'm doing. }\end{array}$ \\
\hline 4_4 & Describing/openness & I'm good at finding the words to describe my feelings. & It's hard for me to find the words to describe what I'm thinking. \\
\hline $5 \_1$ & Non-judgment & I am friendly to myself when things go wrong. & $\begin{array}{l}\text { Usually when I experience distressing thoughts and images... I get } \\
\text { angry that this happens to me. }\end{array}$ \\
\hline $5 \_2$ & Observing & $\begin{array}{l}\text { When I walk outside, I am aware of smells or how the air feels } \\
\text { against my face. }\end{array}$ & I am rarely aware of changes. \\
\hline $5 \_5$ & Self-criticism & I tell myself that I shouldn't have certain thoughts. & $\begin{array}{l}\text { I accept myself the same whatever the thought/image is about in } \\
\text { my mind. }\end{array}$ \\
\hline $5 \_3$ & $\begin{array}{l}\text { Acting with } \\
\text { awareness }\end{array}$ & I find myself doing things without paying attention. & When I do things, my mind wanders off and I'm easily distracted. \\
\hline 5_4 & Describing & I'm good at finding the words to describe my feelings. & It's hard for me to find the words to describe what I'm thinking. \\
\hline $6 \_1$ & $\begin{array}{l}\text { Non-judgment/non- } \\
\text { reacting }\end{array}$ & I am friendly to myself when things go wrong. & I wish I could control my emotions more easily. \\
\hline $6 \_2$ & Observing & $\begin{array}{l}\text { When I walk outside, I am aware of smells or how the air feels } \\
\text { against my face. }\end{array}$ & I am rarely aware of changes. \\
\hline $6 \_3$ & $\begin{array}{l}\text { Acting with } \\
\text { awareness }\end{array}$ & I find myself doing things without paying attention. & When I do things, my mind wanders off and I'm easily distracted. \\
\hline $6 \_5$ & Reacting-judgment & $\begin{array}{l}\text { If there is something I don't want to think about, I'll try many } \\
\text { things to get it out of my mind. }\end{array}$ & $\begin{array}{l}\text { I accept myself the same whatever the thought/image is about in } \\
\text { my mind. }\end{array}$ \\
\hline $6 \_6$ & Describing & I'm good at finding the words to describe my feelings. & It's hard for me to find the words to describe what I'm thinking. \\
\hline $6 \_4$ & $\begin{array}{l}\text { Openness/Western } \\
\text { mindfulness }\end{array}$ & I like to be challenged intellectually. & I am not an original thinker. \\
\hline
\end{tabular}


Table 4 Component loadings of the mindfulness items on the final six components

\begin{tabular}{|c|c|c|c|c|c|c|c|}
\hline $\mathrm{C} 1$ & $\mathrm{C} 5$ & $\mathrm{C} 2$ & $\mathrm{C} 3$ & C6 & C4 & Item & Measure \\
\hline .61 & $\begin{array}{l}- \\
.14\end{array}$ & .09 & .12 & .03 & .06 & I am friendly to myself when things go wrong. & FRBRG \\
\hline .61 & $\begin{array}{l}- \\
.12\end{array}$ & .17 & .12 & .06 & .04 & I am able to appreciate myself. & FRBRG \\
\hline .60 & $\begin{array}{l}- \\
.21\end{array}$ & $\begin{array}{l}- \\
.06\end{array}$ & $\begin{array}{l}- \\
.02\end{array}$ & .19 & $\begin{array}{l}- \\
.01\end{array}$ & I feel calm soon after. & SMQ \\
\hline .58 & $\begin{array}{l}- \\
.23\end{array}$ & .04 & .06 & .08 & .11 & I am able to accept the experience. & SMQ \\
\hline .56 & $\begin{array}{l}- \\
.14\end{array}$ & $\begin{array}{l}- \\
.15\end{array}$ & .03 & .07 & .04 & I just notice them and let them go. & SMQ \\
\hline .55 & $\begin{array}{l}- \\
.04\end{array}$ & .06 & .05 & $\begin{array}{l}- \\
.08\end{array}$ & $\begin{array}{l}- \\
.04\end{array}$ & I see my mistakes and difficulties without judging them. & FRBRG \\
\hline .54 & $\begin{array}{l}- \\
.24\end{array}$ & .06 & $\begin{array}{l}- \\
.01\end{array}$ & .16 & .05 & I "step back" and am aware of the thought or image without getting taken over by it. & SMQ \\
\hline .53 & $\begin{array}{l}- \\
.03\end{array}$ & $\begin{array}{l}- \\
.08\end{array}$ & .11 & .07 & .16 & I watch my feelings without getting lost in them. & FRBRG \\
\hline .52 & $\frac{-}{.29}$ & .17 & .15 & .21 & .09 & I am able to accept the thoughts and feelings I have. & CAMS \\
\hline .51 & $\begin{array}{l}- \\
.30\end{array}$ & .09 & .09 & .09 & $\begin{array}{l}- \\
.04\end{array}$ & I accept myself the same whatever the thought/image is about in my mind. & SMQ \\
\hline .51 & .11 & .18 & .10 & $\begin{array}{l}- \\
.02\end{array}$ & .11 & I am open to the experience of the present moment. & FRBRG \\
\hline .49 & $\begin{array}{l}- \\
.08\end{array}$ & .02 & $\begin{array}{l}- \\
.01\end{array}$ & .12 & $\begin{array}{l}- \\
.07\end{array}$ & I try just to experience the thoughts or images without judging them. & SMQ \\
\hline .49 & .07 & .15 & .29 & .16 & .08 & I am able to focus on the present moment. & CAMS \\
\hline .49 & .14 & .17 & .20 & .13 & .09 & I feel connected to my experience in the here-and-now. & FRBRG \\
\hline .49 & $\begin{array}{l}- \\
.04\end{array}$ & .11 & .12 & .12 & .08 & I experience moments of inner peace and ease, even when things get hectic and stressful. & FRBRG \\
\hline .48 & $\begin{array}{l}- \\
.15\end{array}$ & .25 & .03 & .09 & $\begin{array}{l}- \\
.04\end{array}$ & I try to notice my thoughts without judging them. & CAMS \\
\hline .47 & .00 & .09 & .04 & $-\bar{~}-06$ & .12 & I am able to smile when I notice how I sometimes make life difficult. & FRBRG \\
\hline .46 & $\begin{array}{l}- \\
.15\end{array}$ & $\frac{-}{.21}$ & .03 & .11 & .09 & I am able just to notice them without reacting. & SMQ \\
\hline .46 & $\begin{array}{l}- \\
.03\end{array}$ & .07 & $\begin{array}{l}- \\
.01\end{array}$ & .08 & .10 & I notice how brief the thoughts and images really are. & SMQ \\
\hline .45 & $\begin{array}{l}- \\
.14\end{array}$ & .10 & .12 & .04 & .16 & I can accept things I cannot change. & CAMS \\
\hline $\begin{array}{l}- \\
.44\end{array}$ & .44 & .18 & $\begin{array}{l}- \\
.11\end{array}$ & $\begin{array}{l}- \\
.11\end{array}$ & $\begin{array}{l}- \\
.03\end{array}$ & I wish I could control my emotions more easily. & PHLMS \\
\hline .43 & .03 & .26 & .20 & .06 & .07 & When I notice an absence of mind, I gently return to the experience of the here and now. & FRBRG \\
\hline .38 & $\begin{array}{l}- \\
.19\end{array}$ & $\begin{array}{l}- \\
.02\end{array}$ & $\begin{array}{l}- \\
.02\end{array}$ & .12 & .26 & I can tolerate emotional pain. & CAMS \\
\hline $\begin{array}{l}- \\
.37\end{array}$ & .23 & .29 & $\begin{array}{l}- \\
.31\end{array}$ & $\begin{array}{l}- \\
.10\end{array}$ & $\begin{array}{l}- \\
.05\end{array}$ & I lose myself in the thoughts/images. & SMQ \\
\hline .37 & $\begin{array}{l}- \\
.02\end{array}$ & .09 & .16 & $\begin{array}{l}- \\
.08\end{array}$ & .21 & In difficult situations, I can pause without immediately reacting. & FRBRG \\
\hline$-\overline{36}$ & .35 & .29 & $-\overline{13}$ & $-\overline{.06}$ & $\begin{array}{l}- \\
.04\end{array}$ & They take over my mind for quite a while afterwards. & SMQ \\
\hline .31 & $\begin{array}{l}- \\
.01\end{array}$ & .09 & .03 & .05 & .30 & I accept unpleasant experiences. & FRBRG \\
\hline$-\frac{}{.20}$ & .15 & .12 & $\begin{array}{l}- \\
.15\end{array}$ & $\begin{array}{l}- \\
.03\end{array}$ & .18 & I am preoccupied by the future. & CAMS \\
\hline
\end{tabular}


Table 4 Component loadings of the mindfulness items on the final six components (Continued)

\begin{tabular}{|c|c|c|c|c|c|c|c|}
\hline $\mathrm{C} 1$ & C5 & C2 & C3 & C6 & C4 & Item & Measure \\
\hline .18 & .05 & $\begin{array}{l}- \\
.10\end{array}$ & $\begin{array}{l}- \\
.09\end{array}$ & $\begin{array}{l}- \\
.10\end{array}$ & $\begin{array}{l}- \\
.09\end{array}$ & I seldom notice what other people are up to. & LMS \\
\hline .07 & .69 & .11 & $\begin{array}{l}- \\
.04\end{array}$ & $\begin{array}{l}- \\
.07\end{array}$ & $\begin{array}{l}- \\
.21\end{array}$ & If there is something I don't want to think about, l'll try many things to get it out of my mind. & PHLMS \\
\hline $\begin{array}{l}- \\
.03\end{array}$ & .68 & .04 & $\begin{array}{l}- \\
.10\end{array}$ & $\begin{array}{l}- \\
.07\end{array}$ & $\begin{array}{l}- \\
.08\end{array}$ & I try to stay busy to keep thoughts or feelings from coming to mind. & PHLMS \\
\hline .00 & .66 & .07 & $\begin{array}{l}- \\
.05\end{array}$ & $\begin{array}{l}- \\
.06\end{array}$ & $\begin{array}{l}- \\
.10\end{array}$ & I try to distract myself when I feel unpleasant emotions. & PHLMS \\
\hline $\begin{array}{l}- \\
.31\end{array}$ & .65 & .01 & $\begin{array}{l}- \\
.09\end{array}$ & $\begin{array}{l}- \\
.11\end{array}$ & .08 & I tell myself that I shouldn't have certain thoughts. & PHLMS \\
\hline $\begin{array}{l}- \\
.17\end{array}$ & .65 & .07 & $\begin{array}{l}- \\
.07\end{array}$ & $\begin{array}{l}- \\
.03\end{array}$ & $\begin{array}{l}- \\
.08\end{array}$ & There are things I try not to think about. & PHLMS \\
\hline .04 & .64 & .10 & $\begin{array}{l}- \\
.07\end{array}$ & $\begin{array}{l}- \\
.04\end{array}$ & $\begin{array}{l}- \\
.19\end{array}$ & When I have a bad memory, I try to distract myself to make it go away. & PHLMS \\
\hline .17 & .58 & .03 & $\begin{array}{l}- \\
.20\end{array}$ & $\begin{array}{l}- \\
.04\end{array}$ & $\begin{array}{l}- \\
.19\end{array}$ & I try to put my problems out of mind. & PHLMS \\
\hline $\begin{array}{l}- \\
.35\end{array}$ & .57 & $\begin{array}{l}- \\
.02\end{array}$ & $\begin{array}{l}- \\
.21\end{array}$ & $\begin{array}{l}- \\
.14\end{array}$ & .15 & I tell myself that I shouldn't be feeling the way I'm feeling. & KIMS \\
\hline $\begin{array}{l}- \\
.30\end{array}$ & .56 & .00 & $\begin{array}{l}- \\
.10\end{array}$ & $\begin{array}{l}- \\
.11\end{array}$ & .07 & There are aspects of myself I don't want to think about. & PHLMS \\
\hline $\begin{array}{l}- \\
.12\end{array}$ & .55 & .04 & $\begin{array}{l}- \\
.10\end{array}$ & $\begin{array}{l}- \\
.06\end{array}$ & .03 & I tell myself that I shouldn't feel sad. & PHLMS \\
\hline $\begin{array}{l}- \\
.40\end{array}$ & .55 & $\begin{array}{l}- \\
.06\end{array}$ & $\begin{array}{l}- \\
.19\end{array}$ & $\begin{array}{l}- \\
.13\end{array}$ & .16 & I think some of my emotions are bad or inappropriate and I shouldn't feel them. & KIMS \\
\hline $\begin{array}{l}- \\
.41\end{array}$ & .52 & $\begin{array}{l}- \\
.04\end{array}$ & $\begin{array}{l}- \\
.16\end{array}$ & $\begin{array}{l}- \\
.13\end{array}$ & .19 & I tell myself that I shouldn't be thinking the way I'm thinking. & KIMS \\
\hline $\begin{array}{l}- \\
.41\end{array}$ & .49 & .04 & $\begin{array}{l}- \\
.15\end{array}$ & $\begin{array}{l}- \\
.09\end{array}$ & .20 & I criticize myself for having irrational or inappropriate emotions. & KIMS \\
\hline $\begin{array}{l}- \\
.32\end{array}$ & .48 & .02 & $\begin{array}{l}- \\
.13\end{array}$ & $\begin{array}{l}- \\
.01\end{array}$ & .16 & I disapprove of myself when I have irrational ideas. & KIMS \\
\hline $\begin{array}{l}- \\
.22\end{array}$ & .46 & .08 & $\begin{array}{l}- \\
.17\end{array}$ & $\begin{array}{l}- \\
.15\end{array}$ & $\begin{array}{l}- \\
.07\end{array}$ & I find it so unpleasant I have to distract myself and not notice them. & SMQ \\
\hline $\begin{array}{l}- \\
.35\end{array}$ & .46 & $\begin{array}{l}- \\
.09\end{array}$ & $\begin{array}{l}- \\
.18\end{array}$ & $\begin{array}{l}- \\
.10\end{array}$ & .27 & I believe some of my thoughts are abnormal or bad and I shouldn't think that way. & KIMS \\
\hline $\begin{array}{l}- \\
.31\end{array}$ & .45 & .06 & $\begin{array}{l}- \\
.16\end{array}$ & .02 & .03 & I judge myself as good or bad, depending on what the thought/image is about. & SMQ \\
\hline $\begin{array}{l}- \\
.43\end{array}$ & .44 & .11 & $\begin{array}{l}- \\
.15\end{array}$ & $\begin{array}{l}- \\
.04\end{array}$ & $\begin{array}{l}- \\
.08\end{array}$ & I get angry that this happens to me. & SMQ \\
\hline $\begin{array}{l}- \\
.14\end{array}$ & .41 & .11 & $\begin{array}{l}- \\
.10\end{array}$ & $\begin{array}{l}- \\
.07\end{array}$ & $\begin{array}{l}- \\
.15\end{array}$ & I try and push them away. & SMQ \\
\hline $\begin{array}{l}- \\
.22\end{array}$ & .38 & .22 & $\begin{array}{l}- \\
.04\end{array}$ & .06 & .28 & I make judgments about whether my thoughts are good or bad. & KIMS \\
\hline $\begin{array}{l}- \\
.07\end{array}$ & .33 & .17 & $\begin{array}{l}- \\
.22\end{array}$ & .00 & .21 & I tend to make judgments about how worthwhile or worthless my experiences are. & KIMS \\
\hline $\begin{array}{l}- \\
.26\end{array}$ & .30 & .15 & $\begin{array}{l}- \\
.30\end{array}$ & .07 & .03 & I am preoccupied by the past. & CAMS \\
\hline $\begin{array}{l}- \\
.15\end{array}$ & .29 & .13 & $\begin{array}{l}- \\
.03\end{array}$ & .05 & .03 & I judge the thought/image as good or bad. & SMQ \\
\hline .05 & .20 & .05 & $\begin{array}{l}- \\
.04\end{array}$ & .01 & .14 & When I do things, I get totally wrapped up in them and don't think about anything else. & KIMS \\
\hline $\begin{array}{l}- \\
.03\end{array}$ & -.13 & .05 & $\begin{array}{l}- \\
.01\end{array}$ & $\begin{array}{l}- \\
.09\end{array}$ & $\begin{array}{l}- \\
.07\end{array}$ & I generate few novel ideas. & LMS \\
\hline - & .01 & .67 & .06 & - & .08 & When I walk outside, I am aware of smells or how the air feels against my face. & PHLMS \\
\hline
\end{tabular}


Table 4 Component loadings of the mindfulness items on the final six components (Continued)

\begin{tabular}{|c|c|c|c|c|c|c|c|}
\hline C1 & C5 & C2 & C3 & C6 & C4 & Item & Measure \\
\hline .03 & .00 & .61 & .08 & $\begin{array}{l}- \\
.04\end{array}$ & $\begin{array}{l}- \\
.02\end{array}$ & When I shower, I am aware of how the water is running over my body. & PHLMS \\
\hline .03 & .05 & .59 & .12 & $\begin{array}{l}- \\
.04\end{array}$ & .11 & I notice changes inside my body, like my heart beating faster or my muscles getting tense. & PHLMS \\
\hline .03 & .00 & .58 & .02 & .06 & .10 & I pay attention to sensations, such as the wind in my hair or sun on my face. & KIMS \\
\hline .01 & .01 & .57 & .01 & .05 & .08 & When I am startled, I notice what is going on inside my body. & PHLMS \\
\hline .03 & .20 & .57 & .14 & .28 & $\begin{array}{l}- \\
.02\end{array}$ & When talking with other people, I am aware of the emotions I am experiencing. & PHLMS \\
\hline-.03 & .03 & .56 & .03 & .00 & .04 & When I take a shower or bath, I stay alert to the sensations of water on my body. & KIMS \\
\hline .10 & $\begin{array}{l}- \\
.02\end{array}$ & .55 & .00 & $\begin{array}{l}- \\
.02\end{array}$ & .04 & I notice changes in my body, such as whether my breathing slows down or speeds up. & KIMS \\
\hline-.06 & .00 & .52 & $\begin{array}{l}- \\
.04\end{array}$ & $\begin{array}{l}- \\
.08\end{array}$ & .22 & I pay attention to sounds, such as clocks ticking, birds chirping, or cars passing. & KIMS \\
\hline .08 & $\begin{array}{l}- \\
.02\end{array}$ & .52 & .08 & $\begin{array}{l}- \\
.01\end{array}$ & .05 & I notice the smells and aromas of things. & KIMS \\
\hline .09 & .23 & .51 & .09 & .27 & .01 & I am aware of thoughts I'm having when my mood changes. & PHLMS \\
\hline .02 & .07 & .50 & .05 & .33 & $\begin{array}{l}- \\
.03\end{array}$ & Whenever my emotions change, I am conscious of them immediately. & PHLMS \\
\hline- & $\begin{array}{l}- \\
.03\end{array}$ & .49 & .04 & $-\overline{.01}$ & .41 & I notice visual elements in art or nature, such as colors, shapes, textures, or patterns of light and shadow. & KIMS \\
\hline .09 & .12 & .46 & .11 & .22 & .11 & I am aware of what thoughts are passing through my mind. & PHLMS \\
\hline .15 & .06 & .46 & $\begin{array}{l}- \\
.04\end{array}$ & $\begin{array}{l}- \\
.01\end{array}$ & .10 & I pay attention to whether my muscles are tense or relaxed. & KIMS \\
\hline .15 & .09 & .44 & $\begin{array}{l}- \\
.05\end{array}$ & .21 & .06 & I notice when my moods begin to change. & KIMS \\
\hline .00 & .11 & .43 & .14 & .19 & .07 & When talking with other people, I am aware of their facial and body expressions. & PHLMS \\
\hline .05 & .03 & .42 & $\begin{array}{l}- \\
.14\end{array}$ & .05 & .21 & When I'm walking, I deliberately notice the sensations of my body moving. & KIMS \\
\hline .10 & .16 & .42 & .03 & .28 & .16 & I pay attention to how my emotions affect my thoughts and behavior. & KIMS \\
\hline .28 & .09 & .42 & .11 & .03 & .11 & I sense my body, whether eating, cooking, cleaning, or talking. & FRBRG \\
\hline .14 & .11 & .41 & .08 & .30 & .28 & I intentionally stay aware of my feelings. & KIMS \\
\hline .06 & .12 & .40 & .07 & .10 & .07 & I notice how foods and drinks affect my thoughts, bodily sensations, and emotions. & KIMS \\
\hline$-\overline{33}$ & .31 & .35 & $\begin{array}{l}- \\
.13\end{array}$ & $\overline{-}-01$ & .01 & I keep thinking about the thought or image after it's gone. & SMQ \\
\hline .08 & .12 & $-\overline{.28}$ & $-\overline{.10}$ & $-\overline{.04}$ & $-\overline{.18}$ & I am rarely aware of changes & LMS \\
\hline .17 & $-\overline{.13}$ & .10 & .67 & .12 & .12 & I find myself doing things without paying attention. & MAAS \\
\hline .37 & $\begin{array}{l}- \\
.12\end{array}$ & .03 & .58 & .06 & .04 & I find it difficult to stay focused on what's happening in the present. & MAAS \\
\hline- & .09 & .19 & $\begin{array}{l}- \\
.58\end{array}$ & $-\overline{.23}$ & $\begin{array}{l}- \\
.07\end{array}$ & When I do things, my mind wanders off and I'm easily distracted. & KIMS \\
\hline$-\overline{.10}$ & .00 & .06 & $\begin{array}{l}- \\
.57\end{array}$ & $\begin{array}{l}- \\
.11\end{array}$ & $-\overline{.24}$ & I am easily distracted. & CAMS \\
\hline .07 & $-\overline{.}$ & .06 & .56 & .02 & .22 & I rush through activities without being really attentive to them. & MAAS \\
\hline .24 & $\begin{array}{l}- \\
.23\end{array}$ & .16 & .56 & .15 & .02 & It seems I am "running on automatic," without much awareness of what I'm doing. & MAAS \\
\hline$-\overline{.02}$ & $\begin{array}{l}- \\
.05\end{array}$ & .15 & .54 & .03 & $\begin{array}{l}- \\
.05\end{array}$ & I break or spill things because of carelessness, not paying attention, or thinking of something else. & MAAS \\
\hline- & - & .04 & .53 & .02 & .18 & I snack without being aware that I'm eating. & MAAS \\
\hline
\end{tabular}


Table 4 Component loadings of the mindfulness items on the final six components (Continued)

\begin{tabular}{|c|c|c|c|c|c|c|c|}
\hline$\overline{C 1}$ & C5 & $\mathrm{C} 2$ & $\mathrm{C} 3$ & C6 & C4 & Item & Measure \\
\hline .04 & .10 & & & & & & \\
\hline .04 & $\begin{array}{l}- \\
.17\end{array}$ & .03 & .51 & .04 & $\begin{array}{l}- \\
.11\end{array}$ & I find myself listening to someone with one ear, doing something else at the same time. & MAAS \\
\hline $\begin{array}{l}- \\
.27\end{array}$ & .23 & .02 & $\begin{array}{l}- \\
.50\end{array}$ & $\begin{array}{l}- \\
.21\end{array}$ & $\begin{array}{l}- \\
.06\end{array}$ & I don't pay attention to what I'm doing because I'm daydreaming, worrying, or otherwise distracted. & KIMS \\
\hline .01 & $\begin{array}{l}- \\
.12\end{array}$ & .19 & .48 & .02 & $\begin{array}{l}- \\
.01\end{array}$ & I drive places on "automatic pilot" and then wonder why I went there. & MAAS \\
\hline .30 & .07 & .04 & .46 & .19 & .26 & It is easy for me to concentrate on what I am doing. & CAMS \\
\hline .05 & $\begin{array}{l}- \\
.11\end{array}$ & .16 & .45 & $\begin{array}{l}- \\
.01\end{array}$ & $\begin{array}{l}- \\
.09\end{array}$ & I do jobs or tasks automatically, without being aware of what I'm doing. & MAAS \\
\hline $\begin{array}{l}- \\
.09\end{array}$ & .15 & $\begin{array}{l}- \\
.15\end{array}$ & $\begin{array}{l}- \\
.42\end{array}$ & $\begin{array}{l}- \\
.19\end{array}$ & .02 & I drive on "automatic pilot" without paying attention to what I'm doing. & KIMS \\
\hline .00 & $\begin{array}{l}- \\
.02\end{array}$ & .07 & .40 & .09 & $\begin{array}{l}- \\
.06\end{array}$ & I forget a person's name almost as soon as l've been told it for the first time. & MAAS \\
\hline $\begin{array}{l}- \\
.03\end{array}$ & .04 & .18 & $\begin{array}{l}- \\
.39\end{array}$ & $\begin{array}{l}- \\
.20\end{array}$ & .00 & I tend to do several things at once rather than focusing on one thing at a time. & KIMS \\
\hline .09 & $\begin{array}{l}- \\
.24\end{array}$ & .11 & .39 & .32 & $\begin{array}{l}- \\
.11\end{array}$ & I could be experiencing some emotion and not be conscious of it until some time later. & MAAS \\
\hline .15 & .05 & .05 & .38 & .09 & .30 & I am able to pay close attention to one thing for a long period of time. & CAMS \\
\hline .35 & $\begin{array}{l}- \\
.22\end{array}$ & $\begin{array}{l}- \\
.12\end{array}$ & .36 & $\begin{array}{l}- \\
.04\end{array}$ & $\begin{array}{l}- \\
.07\end{array}$ & I find myself preoccupied with the future or the past. & MAAS \\
\hline .19 & $\begin{array}{l}- \\
.20\end{array}$ & .14 & .34 & .00 & .01 & $\begin{array}{l}\text { I tend to walk quickly to get where I'm going without paying attention to what I experience along the } \\
\text { way. }\end{array}$ & MAAS \\
\hline .19 & -16 & .07 & .33 & - & .01 & $\begin{array}{l}\text { I get so focused on the goal I want to achieve that I lose touch with what I'm doing right now to get } \\
\text { there. }\end{array}$ & MAAS \\
\hline .12 & .18 & $-\overline{0}$ & .30 & .05 & .11 & When I'm doing something, I'm only focused on what I'm doing, nothing else. & KIMS \\
\hline$-\overline{0}$ & .16 & .17 & - & $\begin{array}{l}- \\
.15\end{array}$ & -13 & $\begin{array}{l}\text { When I'm working on something, part of my mind is occupied with other topics, such as what I'll be } \\
\text { doing later, or things I'd rather be doing. }\end{array}$ & KIMS \\
\hline$-\overline{0}$ & -19 & .21 & .26 & .08 & -.03 & I tend not to notice feelings of physical tension or discomfort until they really grab my attention. & MAAS \\
\hline .02 & .04 & .14 & .23 & .04 & .20 & When I'm reading, I focus all my attention on what I'm reading. & KIMS \\
\hline- & .13 & .00 & -19 & $-\overline{0}$ & -.09 & I am impatient with myself and with others. & FRBRG \\
\hline $\begin{array}{l}- \\
.08\end{array}$ & .18 & .02 &.- & $\begin{array}{l}- \\
.76\end{array}$ & -.06 & It's hard for me to find the words to describe what I'm thinking. & KIMS \\
\hline .13 & - & .14 & .14 & .75 & .21 & I'm good at finding the words to describe my feelings. & KIMS \\
\hline$-\overline{0}$ & .19 & .04 & -16 & - & -.08 & I have trouble thinking of the right words to express how I feel about things. & KIMS \\
\hline .12 & -09 & .17 & .10 & .70 & .03 & Even when I'm feeling terribly upset, I can find a way to put it into words. & KIMS \\
\hline .14 & -.07 & .26 & .16 & .67 & .12 & I can usually describe how I feel at the moment in considerable detail. & CAMS \\
\hline .14 & -11 & .20 & .21 & .66 & .09 & When someone asks how I am feeling, I can identify my emotions easily. & PHLMS \\
\hline $\begin{array}{l}- \\
.07\end{array}$ & .13 & .07 & $\begin{array}{l}- \\
.17\end{array}$ & - & -.03 & $\begin{array}{l}\text { When I have a sensation in my body, it's difficult for me to describe it because I can't find the right } \\
\text { words. }\end{array}$ & KIMS \\
\hline .01 & .00 & .24 & -.05 & .56 & .29 & My natural tendency is to put my experiences into words. & KIMS \\
\hline .24 & .00 & .12 & .08 & .55 & .16 & I can easily put my beliefs, opinions, and expectations into words. & KIMS \\
\hline .10 & $\begin{array}{l}- \\
.05\end{array}$ & .26 & .22 & .48 & .25 & I'm good at thinking of words to express my perceptions, such as how things taste, smell, or sound. & KIMS \\
\hline
\end{tabular}


Table 4 Component loadings of the mindfulness items on the final six components (Continued)

\begin{tabular}{|c|c|c|c|c|c|c|c|}
\hline C1 & C5 & $\mathrm{C} 2$ & C3 & C6 & C4 & Item & Measure \\
\hline .35 & $\begin{array}{l}. \\
.06\end{array}$ & .28 & .21 & .45 & .10 & It's easy for me to keep track of my thoughts and feelings. & CAMS \\
\hline .07 & $\begin{array}{l}- \\
.07\end{array}$ & .05 & .17 & .13 & .59 & I like to be challenged intellectually. & LMS \\
\hline .23 & $\begin{array}{l}- \\
.02\end{array}$ & .03 & $\begin{array}{l}- \\
.01\end{array}$ & .06 & .57 & I try to think of new ways of doing things. & LMS \\
\hline .16 & $\begin{array}{l}- \\
.18\end{array}$ & .04 & .05 & .10 & .56 & I find it easy to create new and effective ideas. & LMS \\
\hline .19 & $\begin{array}{l}- \\
.12\end{array}$ & $\begin{array}{l}- \\
.03\end{array}$ & $\begin{array}{l}- \\
.02\end{array}$ & .16 & .51 & I make many novel contributions. & LMS \\
\hline .17 & .09 & .20 & .02 & $\begin{array}{l}- \\
.05\end{array}$ & .51 & I like to figure out how things work. & LMS \\
\hline .08 & $-\overline{.12}$ & .26 & .01 & .07 & .49 & I am very creative. & LMS \\
\hline .12 & .13 & .25 & .02 & $\begin{array}{l}- \\
.07\end{array}$ & .46 & I like to investigate things. & LMS \\
\hline .05 & .08 & $\begin{array}{l}- \\
.09\end{array}$ & $\begin{array}{l}- \\
.17\end{array}$ & $\begin{array}{l}- \\
.18\end{array}$ & $\begin{array}{l}- \\
.45\end{array}$ & I am not an original thinker. & LMS \\
\hline .07 & .08 & $\begin{array}{l}- \\
.10\end{array}$ & $\begin{array}{l}- \\
.06\end{array}$ & $\begin{array}{l}- \\
.16\end{array}$ & $\begin{array}{l}- \\
.43\end{array}$ & I avoid thought provoking conversations. & LMS \\
\hline .14 & .04 & .32 & $\begin{array}{l}- \\
.03\end{array}$ & .04 & .42 & I am very curious. & LMS \\
\hline $\begin{array}{l}- \\
.05\end{array}$ & .23 & .25 & $\begin{array}{l}- \\
.04\end{array}$ & .12 & .39 & I tend to evaluate whether my perceptions are right or wrong. & KIMS \\
\hline .00 & $\begin{array}{l}- \\
.05\end{array}$ & $\begin{array}{l}- \\
.09\end{array}$ & $\begin{array}{l}- \\
.05\end{array}$ & $\begin{array}{l}- \\
.07\end{array}$ & $\begin{array}{l}- \\
.33\end{array}$ & I am rarely alert to new developments. & LMS \\
\hline .17 & .03 & .29 & .21 & .14 & .32 & I pay attention to what's behind my actions. & FRBRG \\
\hline .06 & .15 & .02 & .14 & .06 & .25 & I get completely absorbed in what I'm doing, so that all my attention is focused on it. & KIMS \\
\hline $\begin{array}{l}- \\
.03\end{array}$ & .16 & .13 & $\begin{array}{l}- \\
.15\end{array}$ & $\begin{array}{l}- \\
.12\end{array}$ & .22 & When I'm doing chores, such as cleaning or laundry, I tend to daydream or think of other things. & KIMS \\
\hline
\end{tabular}

C1 non-judgment/non-reacting, C2 observing, C3 acting with awareness, C5 reacting/judgment, C6 describing, C4 openness/Western mindfulness

available on the OSF:(https://osf.io/k2m35/). The final six components were labelled as follows: "Non-Judgement/Non-Reacting", "Observing", "Acting with Awareness", "Reacting/Judgement", "Describing", "Openness/ Western Mindfulness".

When examining the single component extracted first, it was primarily defined by non-judgmental awareness items. This single factor seems to support the interpretation of mindfulness in line with KabatZinn's definition of mindfulness as: "paying attention in a particular way: on purpose, in the present moment, non-judgmentally" (1994, p.4), indicating that the core element of mindfulness is a quality of awareness rather than describing emotions or nonreactance. As can be seen in Fig. 1, observing then split off from this general component. In the third step, a component defined by describing and focus items emerged. This component was positively related to observing and negatively to judgment. In the fourth step, the describing/focus component splits into self-criticism and describing/openness. In the fifth step, self-criticism splits into acting with awareness and self-criticism. In the sixth step, describing/openness splits into describing and openness.

Overall, the first distinct components within the larger structure to emerge were observing and non-judgment in the three-component solution. These components remained uncorrelated to all other components (with the exception of observing being correlated with describing), highlighting the distinctiveness of these mindfulness components from the remainder of the mindfulness construct. A further empirically distinct component was acting with awareness which emerged in the fivecomponent solution, followed by describing and by openness (LMS) in the 6-component solution.

Focusing on the origins of the individual components of the final six-component solution, non-judgment/nonreacting was defined by items of the SMQ and the FMI. Some unique items of the PHLMS, such as "I wish I could control my emotions more easily," showed substantial negative loadings on this component. The items from the LMS did not load substantially on this 


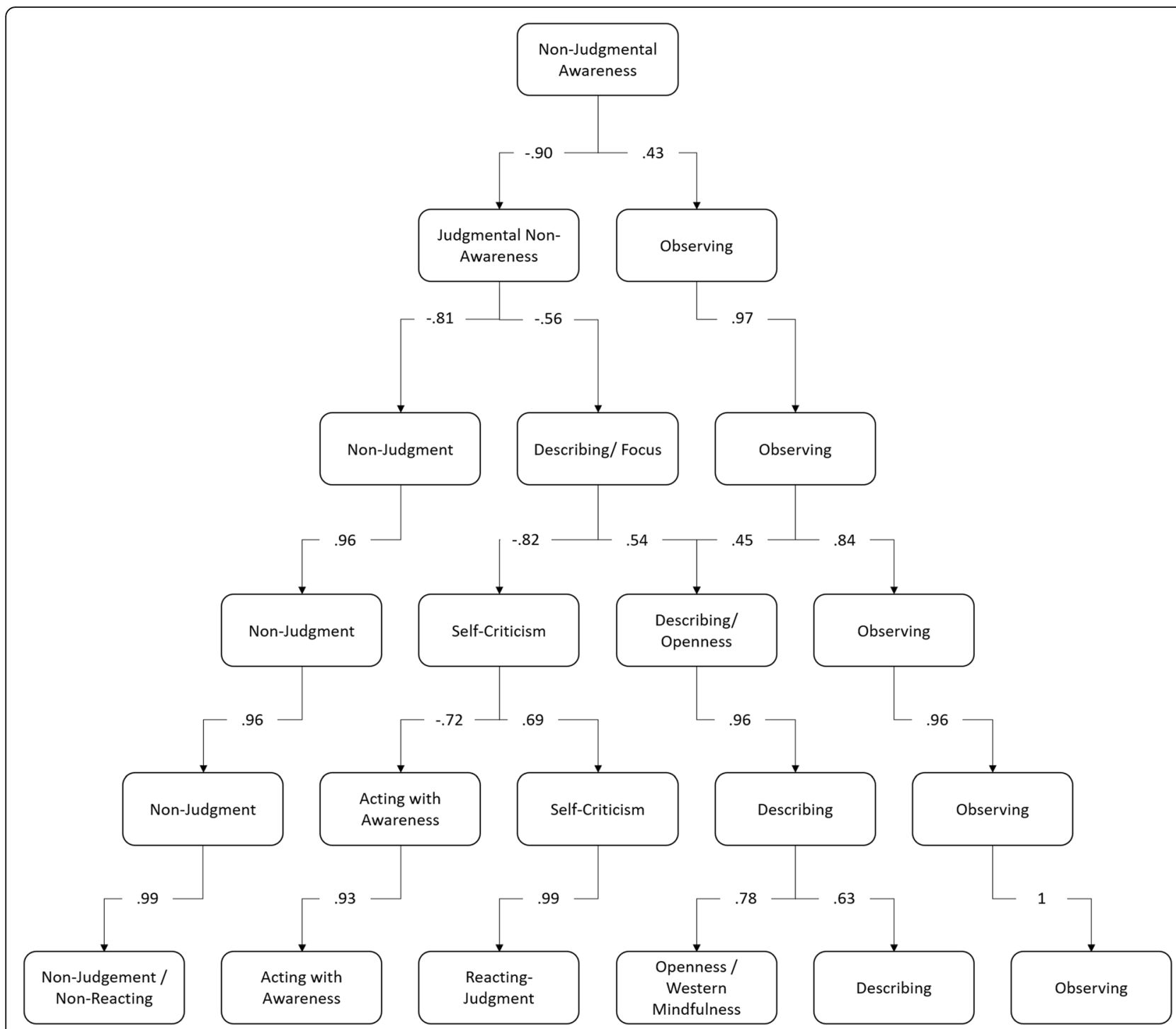

Fig. 1 Unfolding structure of the six-component solution. Each component scores are correlated with component scores at the prior level. We show correlations $r \geq .40$

component. Observing was mostly defined by PHLMS items, such as "When I walk outside, I am aware of smells or how the air feels against my face". Some KIMS items measuring observing, such as "I pay attention to sensations, such as the wind in my hair or sun on my face" also loaded on this component. Overall, we did not find substantial negative loadings on this component. Acting with awareness was positively defined by reverse keyed MAAS items, such as "I find myself doing things without paying attention," and negatively defined by KIMS items, such as "When I do things, my mind wanders off and I'm easily distracted". We found no substantial loadings of either LMS or PHLMS items. Reacting/ judgment was largely defined by PHLMS items, such as "If there is something I don't want to think about, I'll try many things to get it out of my mind". A number of
KIMS items, such as "I tell myself that I shouldn't be feeling the way I'm feeling.", also loaded positively on the component. We did not find substantial negative loadings on this component. Describing was positively defined by KIMS items, such as "I'm good at finding the words to describe my feelings," and negatively by KIMS items, such as "It's hard for me to find the words to describe what I'm thinking". We did not find substantial loadings of the LMS and only one item "When someone asks how I am feeling, I can identify my emotions easily" of the PHLMS loaded substantially. Last, openness/ Western mindfulness was largely defined by LMS items, such as "I like to be challenged intellectually". The only two non-LMS item loading substantially positively on the component were from the KIMS "I notice visual elements in art or nature, such as colors, shapes, textures, 
or patterns of light and shadow" and "I tend to evaluate whether my perceptions are right or wrong." Substantial negative loading items were exclusively LMS items, such as "I am not an original thinker".

As suggested by an anonymous reviewer, to examine the possibility of a general response factor, we ran confirmatory factor analysis with lavaan using a WLSMV estimator (for further model specifications and analytical code, see the supplementary material on the OSF). We fitted a model in which each item loaded on the factor on which it showed the highest loading in the exploratory factor analysis reported above. Additionally, all items were loaded on a separate general response factor, which was uncorrelated with the substantive factors. Item loadings were freely estimated by standardizing the latent variable. The relative fit of the six-factor structure is significantly improved when including a general response factor $\triangle \mathrm{CFI}$ from the model without response factor, .087. Unfortunately, we were unable to fully explore positively vs negatively wording factors because the emerging factors in our analysis were not wellbalanced in their phrasing. In order to disentangle possible content and method-artifacts, future studies need to include balanced item sets using both positively and negatively phrased items across all domains. Our exploratory findings suggest that item wording effects need greater attention in the measurement of mindfulness.

\section{Discussion}

The goal of the current research was to examine whether the commonly accepted multidimensional structure of mindfulness as exemplified in the FFMQ can be conceptually replicated using measures originally included in the development of the FFMQ while also including additional theoretically similar (PHLMS) and dissimilar (LMS) measures.

While we recovered three facets that expressed the same content as observing, describing, and acting with awareness in the FFMQ, we did not find separate nonjudging and non-reacting components. This indicates that the distinction between those two components of mindfulness requiring distinct cognitive and behavioral reactions, while theoretically important, might not be sufficiently clear and distinct for participants in our sample. Both components require adaptation of cognitive and behavioral responses after noticing internal or external sensations, emotions, and thoughts. These distinctions appear to be too subtle, as these two factors merged to a generic non-reactivity factor in our sample. Similar factors combining non-judgment and nonreaction have been reported in other instruments (for example the CAMS-R, PHLMS). At the same time, when including an additional measure of mindfulness with a distinct philosophical background, we identified an additional factor. Overall, this indicates that while some individual components can be recovered and are broadly in line with previous conceptualizations of mindfulness, we did not recover the complete structure of the FFMQ with all its nuances and it may miss additional components of interest to mindfulness researchers.

We also found that openness/Western conceptualization of mindfulness emerged as a clearly defined separate component. This supports the theoretical separation of these measures because openness as a core component of a Western mindfulness definition can be empirically separated from items supposed to measure Easternphilosophical perspectives on mindfulness (Pirson et al., 2018). Interestingly, the LMS is supposed to show a threedimensional structure, but in our sample the overall fit for the three factors was poor, and in the item level analysis, a single distinct factor emerged. At the same time, our examination of the unfolding component structure provides important insight into the components that the Eastern and Western conceptualizations of mindfulness share, which helps to explain positive relationships between the LMS and the FFMQ reported in previous research (Siegling \& Petrides, 2016, 2014). The positive relationship of the $L M S$ noted in previous research might be due to the describing facet of the FFMQ (the describing facet showed the strongest positive correlations with the LMS during validation studies, see Pirson et al., 2018). In the current study the LMS/openness components were most clearly associated with describing during the unfolding of the facture structure, and the LMS/openness only splits from this factor and emerged as a separate factor when six components were extracted. This suggests that the ability to describe one's feelings and experiences is an important correlate of being open for new experience as well as enjoying those experiences. Therefore, our analysis suggests that even though Western conceptualizations of mindfulness draw upon different philosophical traditions, the relevant social and cognitive components might still be shared with Eastern-based conceptualizations of mindfulness.

We found a component that expressed judging/reacting and was mostly defined by negatively worded items. This further highlights possible method artifacts in the measurement of mindfulness (Aguado et al., 2015). Studies using a person-centered approach to the FFMQ found a profile that was defined by judging, rather than non-judging (e.g., Bravo, Boothe, \& Pearson, 2016; Pearson, Lawless, Brown, \& Bravo, 2015). These patterns raise the possibility that a number of reversely worded items, possibly from the non-judging or non-reacting facets, do not measure the polar opposites of the positively worded items, but rather tap into a separate construct masked as a response style component. This is a finding consistent with previous studies that found that the fit of the FFMQ can be improved through a bi-factor 
model, indicating the potential presence of a g-factor of mindfulness explaining variance beyond the individual facets (Aguado et al., 2015; Van Dam, Hobkirk, DanoffBurg, \& Earleywine, 2012). The interpretation of bifactor models has been controversial (Bonifay et al., 2017) and further research is needed to understand the meaning of such a factor in the context of mindfulness

\section{Strengths}

Our current study brings together theoretically similar and distinct measures of mindfulness, highlighting the general robustness of the FFMM and appropriateness of the FFMQ to measure mindfulness. It also shows that it is possible to discriminate Western-based conceptualizations of mindfulness from Eastern mindfulness measures. At the same time, it appears that Western-based measures of mindfulness may tap into similar social and cognitive processes that are also fundamental to the traits and abilities captured by Eastern-based mindfulness measures. We used a shortened version of the FMI; therefore, our current study did not employ the exact measures of the study conducted by Baer et al. (2006). Nevertheless, we only recovered three facets (observing, describing, acting with awareness), and one facet that expressed a combination of non-reacting/non-judging. Together with our finding that some items form a negative wording factor, this indicates that the current dimensional conceptualization of mindfulness might need revision.

\section{Limitations}

A limitation of our current study, while still closely resembling the sample used by Baer et al. (2006) during the development of the FFMQ, is the use of a sample of young adults in a Western educational context with a low percentage of active meditators. Previous research found that the observing facet is more strongly related to the general factor of mindfulness in samples with meditation experience (Lilja, Lundh, Josefsson, \& Falkenström, 2013). However, our New Zealand-based sample is conceptually interesting because New Zealand has an official bi-cultural status, in which the national culture is actively co-constructed from both Western influences and traditional Maori culture (for a concise review of New Zealand history see: Mein Smith, 2011). This bicultural model undergirds the social and educational context which has led to more nuanced perceptions of the mind-body duality in a general population compared to North American or Western European settings. This interweaving of cultural practices is increasingly recognized, and more explicit connections between specific Maori cultural practices and Eastern-based mindfulness practices are explored (Higgins \& Eden, 2018). Therefore, the insights from this sample are informative even in the absence of a larger number of meditators or mindfulness practitioners.

\section{Conclusions}

Overall, we found that three of the five FFMM components (observing, describing, acting with awareness) emerged in a conceptual replication and two of the factors merged, which has been found in the structures of other mindfulness instruments. This indicates potentially simpler cognitive and behavioral mindfulness components in lay audiences than indicated by the FFMM. Furthermore, conceptually distinct LMS items emerged as a separate component, highlighting that (a) at least three of the five dimensions of the FFMQ seem to reliably emerge even if new measures of mindfulness are included and (b) that there might be additional components of mindfulness from a Western perspective that are not captured in the FFMM. A third important insight from the unfolding analysis is that the different facets capture distinct aspects of mindfulness with low intercorrelations across some of the facets across the different levels of unfolding, which implies that it is more relevant to use mindfulness scores at a facet level rather than as a general score. Finally, negative wording effects were also apparent, and a number of the negative items might not tap into the proposed concepts but rather capture response tendencies.

\section{Supplementary information}

Supplementary information accompanies this paper at https://doi.org/10. 1186/s42409-020-00014-3.

Additional file 1:. Supplementary material.

\section{Acknowledgements}

Not applicable

\section{Authors' contributions}

JK conceptualized the study and analyzed the data; JK and RF jointly wrote the manuscript. The final version was approved by all authors.

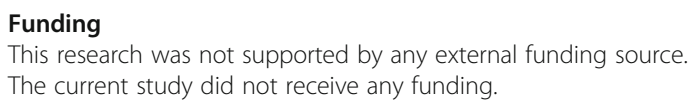

Availability of data and materials

All materials, data, and analytic code is available on the OSF (https://osf.io/k2 $\mathrm{m} 35 /$ )

\section{Ethics approval and consent to participate}

The authors declare that they have no conflict of interest. Participants took part in the current research for course credit as part of an Introduction to Psychology course. Ethical approval was given by the School of Psychology Human Ethics Committee under delegated authority of Victoria University of Wellington's Human Ethics Committee.

Competing interests

The authors declare that they have no competing interests. 


\section{Author details}

${ }^{1}$ Victoria University of Wellington, Wellington, New Zealand. ${ }^{2}$ Instituto D'Or de Pesquisa e Ensino, Sao Paulo, Brazil.

Received: 24 August 2019 Accepted: 23 April 2020

Published online: 24 May 2020

\section{References}

Aguado, J., Luciano, J. V, Cebolla, A., Serrano-Blanco, A., Soler, J., \& GarcíaCampayo, J. (2015). Bifactor analysis and construct validity of the five facet mindfulness questionnaire (FFMQ) in non-clinical Spanish samples. Frontiers in Psychology, 6, 404. https://doi.org/10.3389/fpsyg.2015.00404

Baer, R. A., Smith, G. T., \& Allen, K. B. (2004). Assessment of mindfulness by selfreport: The Kentucky inventory of mindfulness skills. Assessment, 11(3), $191-$ 206. https://doi.org/10.1177/1073191104268029.

Baer, R. A., Smith, G. T., Hopkins, J., Krietemeyer, J., \& Toney, L. (2006). Using selfreport assessment methods to explore facets of mindfulness. Assessment, 13(1), 27-45. https://doi.org/10.1177/1073191105283504.

Bergomi, C., Tschacher, W., \& Kupper, Z. (2013a). Measuring mindfulness: First steps towards the development of a comprehensive mindfulness scale. Mindfulness, 4(1), 18-32. https://doi.org/10.1007/s12671-012-0102-9.

Bergomi, C., Tschacher, W., \& Kupper, Z. (2013b). The assessment of mindfulness with self-report measures: Existing scales and open issues. Mindfulness, 4(3), 191-202. https://doi.org/10.1007/s12671-012-0110-9.

Blasberg, S. A., Rogers, K. H., \& Paulhus, D. L. (2014). The Bidimensional Impression Management Index (BIMI): Measuring agentic and communal forms of impression management. Journal of Personality Assessment, 96(5), 523-531. https://doi.org/10.1080/00223891.2013.862252.

Bonifay, W., Lane, S. P., \& Reise, S. P. (2017). Three concerns with applying a bifactor model as a structure of psychopathology. Clinical Psychological Science, 5(1), 184-186. https://doi.org/10.1177/2167702616657069.

Bravo, A. J., Boothe, L. G., \& Pearson, M. R. (2016). Getting personal with mindfulness: a latent profile analysis of mindfulness and psychological outcomes. Mindfulness, 7(2), 420-432. https://doi.org/10.1007/s12671-0150459-7.

Brown, K. W., \& Ryan, R. M. (2003). The benefits of being present: Mindfulness and its role in psychological well-being. Journal of Personality and Social Psychology, 84(4), 822-848. https://doi.org/10.1037/0022-3514.84.4.822.

Cardaciotto, L., Herbert, J. D., Forman, E. M., Moitra, E., \& Farrow, V. (2008). The assessment of present-moment awareness and acceptance. Assessment, 15(2), 204-223. https://doi.org/10.1177/1073191107311467.

Carlson, L. E., \& Brown, K. W. (2005). Validation of the mindful attention awareness scale in a cancer population. Journal of Psychosomatic Research, 58(1), 29-33. https://doi.org/10.1016/j.jpsychores.2004.04.366.

Chadwick, P., Hember, M., Symes, J., Peters, E., Kuipers, E., \& Dagnan, D. (2008). Responding mindfully to unpleasant thoughts and images: Reliability and validity of the Southampton mindfulness questionnaire (SMQ). British Journal of Clinical Psychology, 47(4), 451-455. https://doi.org/10.1348/ $014466508 \times 314891$

Corr, P. J., \& Cooper, A. J. (2016). The Reinforcement Sensitivity Theory of Personality Questionnaire (RST-PQ): Development and validation. Psychological Assessment, 28(11), 1427-1440. https://doi.org/10.1037/ pas0000273.

De Raad, B., Barelds, D. P. H., Timmerman, M. E., De Roover, K., Mlačić, B., \& Church, A. T. (2014). Towards a pan-cultural personality structure: Input from 11 psycholexical studies. European Journal of Personality, 28(5), 497-510. https://doi.org/10.1002/per.1953.

De Raad, B., \& Van Oudenhoven, J. P. (2008). Factors of values in the Dutch language and their relationship to factors of personality. European Journal of Personality, 22(2), 81-108. https://doi.org/10.1002/per.667.

De Raad, B., \& Van Oudenhoven, J. P. (2011). A psycholexical study of virtues in the Dutch language, and relations between virtues and personality. European Journal of Personality, 25(1), 43-52. https://doi.org/10.1002/per.777.

Diener, E., Emmons, R. A., Larsen, R. J., \& Griffin, S. (1985). The satisfaction with life scale. Journal of Personality Assessment, 49(1), 71-75. https://doi.org/10.1207/ s15327752jpa4901_13.

Diener, E., Wirtz, D., Tov, W., Kim-Prieto, C., Choi, D., Oishi, S., \& Biswas-Diener, R. (2010). New well-being measures: Short scales to assess flourishing and positive and negative feelings. Social Indicators Research, 97(2), 143-156. https://doi.org/10.1007/s11205-009-9493-y.
Feldman, G., Hayes, A., Kumar, S., Greeson, J., \& Laurenceau, J.-P. (2007). Mindfulness and emotion regulation: The development and initial validation of the Cognitive and Affective Mindfulness Scale-Revised (CAMS-R). Journal of Psychopathology and Behavioral Assessment, 29(3), 177-190. https://doi.org/10. 1007/s10862-006-9035-8.

Glorfeld, L. W. (1995). An improvement on Horn's parallel analysis methodology for selecting the correct number of factors to retain. Educational and Psychological Measurement, 55(3), 377-393. https://doi.org/10.1177/ 0013164495055003002

Goldberg, L. R. (2006). Doing it all bass-ackwards: The development of hierarchical factor structures from the top down. Journal of Research in Personality, 40(4), 347-358. https://doi.org/10.1016/j.jp.2006.01.001.

Gu, J., Strauss, C., Crane, C., Barnhofer, T., Karl, A., Cavanagh, K., \& Kuyken, W. (2016). Examining the factor structure of the 39-item and 15-item versions of the Five Facet Mindfulness Questionnaire before and after mindfulness-based cognitive therapy for people with recurrent depression. Psychological Assessment, 28(7), 791-802. https://doi.org/10.1037/pas0000263.

Higgins, J., \& Eden, R. (2018). Emerging understandings of mindfulness through experiential awareness. Learning, 4(1), 102-111. https://doi.org/10.1080/ 23735082.2018.1428144

Horn, J. L. (1965). A rationale and test for the number of factors in factor analysis. Psychometrika, 30(2), 179-185. https://doi.org/10.1007/BF02289447.

Hu, L., \& Bentler, P. M. (1999). Cutoff criteria for fit indexes in covariance structure analysis: Conventional criteria versus new alternatives. Structural Equation Modeling: A Multidisciplinary Journal, 6(1), 1-55. https://doi.org/10.1080/ 10705519909540118 .

Kabat-Zinn, J. (1994). Wherever you go, there you are: Mindfulness meditation in everyday life. New York: Hyperion.

Kucinskas, J. (2014). The unobtrusive tactics of religious movements. Sociology of Religion, 75(4), 537-550. https://doi.org/10.1093/socrel/sru055.

Kucinskas, J. (2018). The mindful elite: mobilizing from the inside out. New York: Oxford University Press.

Li, C.-H. H. (2016). Confirmatory factor analysis with ordinal data: Comparing robust maximum likelihood and diagonally weighted least squares. Behavior Research Methods, 48(3), 936-949. https://doi.org/10.3758/s13428-015-0619-7.

Lilia, J. L., Lundh, L.-G., Josefsson, T., \& Falkenström, F. (2013). Observing as an essential facet of mindfulness: A comparison of FFMQ patterns in meditating and non-meditating individuals. Mindfulness, 4(3), 203-212. https://doi.org/10. 1007/s12671-012-0111-8.

MacCallum, R. C., Browne, M. W., \& Sugawara, H. M. (1996). Power analysis and determination of sample size for covariance structure modeling. Psychological Methods, 1(2), 130-149. https://doi.org/10.1037/1082-989X.1.2.130.

Magnusson, D. (1992). Back to the phenomena: Theory, methods, and statistics in psychological research. European Journal of Personality, 6(1), 1-14. https://doi. org/10.1002/per.2410060102.

Marsh, H. W., Hau, K.-T., \& Wen, Z. (2004). In search of golden rules: Comment on hypothesis-testing approaches to setting cutoff values for fit indexes and dangers in overgeneralizing Hu and Bentler's (1999) findings. Structural Equation Modeling: A Multidisciplinary Journal, 11(3), 320-341. https://doi.org/ 10.1207/s15328007sem1103_2.

Maydeu-Olivares, A. (2017). Maximum likelihood estimation of structural equation models for continuous data: Standard errors and goodness of fit. Structural Equation Modeling: A Multidisciplinary Journal, 24(3), 383-394. https://doi.org/ 10.1080/10705511.2016.1269606.

McNeish, D. (2018). Thanks coefficient alpha, we'll take it from here. Psychological Methods, 23(3), 412-433. https://doi.org/10.1037/met0000144.

Mein Smith, P. (2011). A concise history of New Zealand. Cambridge University Press. https://doi.org/10.1017/CBO9781139196574.

Paulhus, D. L., \& Reid, D. B. (1991). Enhancement and denial in socially desirable responding. Journal of Personality and Social Psychology, 60(2), 307-317. https://doi.org/10.1037/0022-3514.60.2.307

Pearson, M. R., Lawless, A. K., Brown, D. B., \& Bravo, A. J. (2015). Mindfulness and emotional outcomes: Identifying subgroups of college students using latent profile analysis. Personality and Individual Differences, 76, 33-38. https://doi. org/10.1016/j.paid.2014.11.009.

Peters, G.-J. Y. (2018). \{userfriendlyscience\}: Quantitative analysis made accessible. https://doi.org/10.17605/osf.io/txequ

Pirson, M. A., Langer, E., Zilcha, Sigal, \& Zilcha, S. (2018). Enabling a sociocognitive perspective of mindfulness: The development and validation of the Langer mindfulness scale. Journal of Adult Development, 25(3), 168-185. https://doi.org/10.1007/s10804-018-9282-4 
Pirson, M. A., Langer, E. J., Bodner, T., \& Zilcha, S. (2012). The development and validation of the Langer mindfulness scale - Enabling a socio-cognitive perspective of mindfulness in organizational contexts. SSRN Electronic Journal. https://doi.org/10.2139/ssrn.2158921.

Revelle, W. (2018). psych: Procedures for psychological, psychometric, and personality research. Evanston, Illinois. Retrieved from https://cran.r-project. org/package= psych

Sauer, S., Walach, H., Schmidt, S., Hinterberger, T., Lynch, S., Büssing, A., \& Kohls, N. (2013). Assessment of mindfulness: Review on state of the art. Mindfulness, 4(1), 3-17. https://doi.org/10.1007/s12671-012-0122-5.

Schwartz, S. H., Cieciuch, J., Vecchione, M., Davidov, E., Fischer, R., Beierlein, C., et al. (2012). Refining the theory of basic individual values. Journal of Personality and Social Psychology, 103(4), 663-688. https://doi.org/10.1037/ a0029393.

Siegling, A. B., \& Petrides, K. V. (2014). Measures of trait mindfulness: Convergent validity, shared dimensionality, and linkages to the five-factor model. Frontiers in Psychology, 5, 1164. https://doi.org/10.3389/fpsyg.2014.01164.

Siegling, A. B., \& Petrides, K. V. (2016). Zeroing in on mindfulness facets: Similarities, validity, and dimensionality across three independent measures PLOS ONE, 11(4), e0153073. https://doi.org/10.1371/journal.pone.0153073.

Silberzahn, R., Uhlmann, E. L., Martin, D. P., Anselmi, P., Aust, F., Awtrey, E., et al. (2018). Many analysts, one data set: Making transparent how variations in analytic choices affect results. Advances in Methods and Practices in Psychological Science, 1(3), 337-356. https://doi.org/10.1177/ 2515245917747646

Soto, C. J., \& John, O. P. (2017). The next Big Five Inventory (BFl-2): Developing and assessing a hierarchical model with 15 facets to enhance bandwidth, fidelity, and predictive power. Journal of Personality and Social Psychology, 113(1), 117-143. https://doi.org/10.1037/pspp0000096.

Tellis, G. J. (2017). Interesting and impactful research: on phenomena, theory, and writing. Journal of the Academy of Marketing Science, 45(1), 1-6. https://doi. org/10.1007/s11747-016-0499-0.

Trizano-Hermosilla, I., \& Alvarado, J. M. (2016). Best alternatives to Cronbach's alpha reliability in realistic conditions: congeneric and asymmetrical measurements. Frontiers in Psychology, 7, 769. https://doi.org/10.3389/fpsyg. 2016.00769.

Van Dam, N. T., Hobkirk, A. L., Danoff-Burg, S., \& Earleywine, M. (2012). Mind your words: Positive and negative items create method effects on the five facet mindfulness questionnaire. Assessment, 19(2), 198-204. https://doi.org/10. 1177/1073191112438743.

Walach, H., Buchheld, N., Buttenmüller, V., Kleinknecht, N., \& Schmidt, S. (2006). Measuring mindfulness - the Freiburg Mindfulness Inventory (FMI). Personality and Individual Differences, 40(8), 1543-1555. https://doi.org/10. 1016/J.PAID.2005.11.025

Wheaton, B., Muthen, B., Alwin, D. F., \& Summers, G. F. (1977). Assessing reliability and stability in panel models. Sociological Methodology, 8, 84. https:/doi.org/ 10.2307/270754.

Williams, M. J., Dalgleish, T., Karl, A., \& Kuyken, W. (2014). Examining the factor structures of the Five Facet Mindfulness Questionnaire and the SelfCompassion Scale. Psychological Assessment, 26(2), 407-418. https://doi.org/ 10.1037/a0035566.

\section{Publisher's Note}

Springer Nature remains neutral with regard to jurisdictional claims in published maps and institutional affiliations.

Ready to submit your research? Choose BMC and benefit from:

- fast, convenient online submission

- thorough peer review by experienced researchers in your field

- rapid publication on acceptance

- support for research data, including large and complex data types

- gold Open Access which fosters wider collaboration and increased citations

- maximum visibility for your research: over $100 \mathrm{M}$ website views per year

At BMC, research is always in progress.

Learn more biomedcentral.com/submissions 